\title{
Nutrition Awareness and Oral Health among Dental Patients in Palestine: A Cross-Sectional Study
}

\author{
Manal M. H. Badrasawi $\mathbb{D}^{1},{ }^{1}$ Nour H. Hijjeh, ${ }^{2}$ Rana S. Amer, ${ }^{2}$ Reema M. Allan, ${ }^{2}$ \\ and Mohammad Altamimi ${ }^{1}$ \\ ${ }^{1}$ Department of Nutrition and Food Technology, Faculty of Agriculture and Veterinary Medicine, An-Najah National University, \\ Nablus 30500, State of Palestine \\ ${ }^{2}$ Healthy and Therapeutic Nutrition Program, Faculty of Applied Sciences, Palestine Polytechnic University, Hebron 30500, State \\ of Palestine
}

Correspondence should be addressed to Manal M. H. Badrasawi; manalpharmacist@gmail.com

Received 14 August 2019; Revised 20 January 2020; Accepted 24 January 2020; Published 26 February 2020

Academic Editor: Alessandro Leite Cavalcanti

Copyright ( $\odot 2020$ Manal M. H. Badrasawi et al. This is an open access article distributed under the Creative Commons Attribution License, which permits unrestricted use, distribution, and reproduction in any medium, provided the original work is properly cited.

\begin{abstract}
Nutrition plays a key role in oral and dental health. Similarly, oral health affects nutrition status and diet intake. Consumption of much cariogenic nutrients such as sugar affects dental and gum health. The awareness of dietary practices that affect the oral health is an essential component in the dental care system. The knowledge of the dietary factors that affect the oral health is a major component in the treatment plan. In this vein, this study was conducted to determine the level of awareness of nutrition information affecting oral health among dental patients who visit the private and university dental clinics in West Bank, Palestine. A total of 169 patients were invited to join the study and signed the consent form. A pretested questionnaire was used to collect the required data which included patients' sociodemographics, medical history, oral care practices, dietary practices, and oral healthrelated nutritional awareness. Face and content validity were verified, followed by a pilot study to determine the questionnaire reliability alpha, and the data were collected from October to November 2018. The Construct Validation was done using the Rasch measurement model, and the descriptive statistical analysis was done to determine the level of awareness and the difference among the groups using SPSS version 21. The total mean score of the nutrition awareness was $(9.3 \pm 2.8)$, with higher level of nutrition awareness among females, and the highest score was 16 out of 17 . The good oral health condition was reported among $44 \%$, fair $32 \%$, poor $16 \%$, and bad $10 \%$ while excellent oral health was reported among only $5 \%$ of the participants. There was no significant relationship between level of nutritional awareness with economic status, level of education, or area of living. For oral health, females showed significantly better oral and gum health levels $(p<0.05)$. The overall level of nutrition knowledge among the participants is insufficient. These results point to the need for oral health and nutrition educational courses and programs to improve oral and nutritional awareness and knowledge among Palestinian people and dental patients in particular. Improving the dietary habits and oral practices with lifestyle changes should also be encouraged.
\end{abstract}

\section{Introduction}

Oral diseases are the most common noncommunicable diseases (NCDs) spread in developed and developing countries. They are among the major public health problems worldwide that have affected half of the world's population (i.e., about 3.58 billion people) [1]. Such diseases include dental caries, periodontal disease, tooth loss, oral mucosal lesions, and oropharyngeal cancers. In addition to, human immunodeficiency virus/acquired immunodeficiency syndrome (HIV/AIDS) related oral disease and orodental trauma [1]. Oral health is an essential part in general health. It affects and is affected by nutritional status and overall health status. Moreover, it has an impact on the quality of life and health outcomes of the patient [2]. Poor oral health is associated with many chronic diseases such as diabetes mellitus, cardiovascular diseases, respiratory infections, and gastrointestinal pathologies. Moreover, poor oral health has 
been associated with low birth weight and preterm delivery [2]. On the other hand, good nutrition enhances healthy teeth and gum development and reduces the risk of some oral diseases [3]. Both macronutrients and micronutrients have an impact on oral health, teeth development, enamel and dentin synthesis, dental mineralization, and tooth protection [3].

Dental caries is a disease that results from microbiome dysbiosis with the involvement of multiple cariogenic species, including mutans streptococci (MS), lactobacilli, Scardovia wiggsiae, and several Actinomyces species that have the cariogenic traits of acid production and acid tolerance [4]. The relationship between nutrition and dental caries is a well-defined relationship; the anaerobic metabolism of dietary sugar by certain bacteria in the cavity leads to demineralization of enamel and dentin of the tooth by organic acid metabolites [5]. Depending on this mechanism, food items are categorized according to their effect on teeth into cariogenic, cariostatic, and anticariogenic food [3]. The carcinogenicity of food depends on bioavailability, digestibility, and texture of the consumed food [6]. Meaning that liquid food is less cariogenic than solid, while chewy food is less cariogenic than sticky ones $[3,5,6]$. Type of sugar also plays a specific role; that is, lactose has less effect than other sugars; and xylitol (alcohol sugar) reduces the risk of caries through its inhibitory effect on bacterial growth. Consumption of food and drinks that affect the oral cavity acidity (soft drinks, sweetened coffee and tea, candies) leads to teeth demineralization and causes tooth decay [7].

Previous findings have highlighted the preference of consuming fresh fruits to fruits juices because chewing stimulates more saliva production and promotes washing effect; and fruit juices may have extrinsic sugars and lower $\mathrm{pH}$ that contributes to erosive tooth wear. Concerning the meal patterns, it was reported that less frequent meals are recommended over more frequent meals due to their effect on dental caries; similarly, eating dessert after meals is preferred compared to eating them after a period of time [8].

Nutrition education on oral and dental health plays a vital role in preventing oral diseases and related problems. Hence, it should be included in management plans for any dental or oral problems. It maintains good oral health, enhances treatment outcomes, and prevents further dental problems. Higher nutritional knowledge is associated with better eating behaviors and with better nutritional status [9].

To the best of the researchers' knowledge, studies conducted to assess oral health nutrition related knowledge among dental patients or any age groups are very sparse. On the contrary, there are many studies conducted to assess the awareness, practices, and attitudes on oral health in general, without focusing on nutrition related knowledge among secondary school students $[10,11]$, primary schools students [12], housewives and mothers [13], and adults [14]. Some studies go further to assess the pediatricians' knowledge on dental caries prevention [15]. In Saudi Arabia, a knowledge, attitude, and practices study was conducted to explore the awareness level of oral health practices among adolescents age 10-18 years. It has found sufficient level of awareness without significant differences between males and females
[16] while a study conducted on school teachers in India found that a fair level of oral health awareness was reported.

Having searched scientific databases including PubMed, Springer's, Science Direct, and Scopus, it was noticed that literature was lacking studies reporting knowledge or awareness of public or dental patients regarding the nutritional factors that affect oral health. A study was conducted in India to assess students' knowledge in nutrition and oral health relationship [8] and has found a low level of dental nutrition knowledge whose significance has differed according to the student's year of study. In Palestine, a study to address the relationship between oral health and nutritional knowledge among dental patients was recommended. Therefore, this study was designed to fill in such a gap by determining the levels of factors of oral health related nutritional knowledge.

\section{Materials and Methods}

2.1. Study Design. This study utilized the cross-sectional survey design. The main aim was to assess the level of nutrition and oral health awareness and to determine the relationship between nutritional status, oral practices, and oral health among adult patients.

The Al-Quds University Ethical committee approved the study protocol (reference number (55/REC/2018)). The researchers briefed the participants about the objectives of the study and gave them the right to participate in or withdraw from the study at any time. The researchers then obtained signed consent forms. The data collection has taken two months from October to November 2018. The data included participants' sociodemographics, medical history, oral health related practices, nutritional status assessments, oral health related nutrition knowledge, and oral health status.

2.2. Sample Size and Sampling Procedures. Sample size was calculated using G-power software for $t$-test with predetermined margin of error of 5\% and confidence level of 95\%. The required sample size was 120 participants. Thirty participants were added in case of the drop out given a total of 150 participants were recruited using the convenient sampling techniques. Eligible participants had to be adults aged 18-60 years and who had visited the dental clinic for treatment, scaling, or follow-up. The participants with congenital oral problems or under chemotherapy of radiotherapy were excluded from the final analysis. The selected participants were invited to fill in the questionnaire without referring to any information resources while answering the questions. No incentive was provided to the participants.

\subsection{Research Instrument}

2.3.1. Nutritional Knowledge Questionnaire Development. The items of the questionnaire were developed based on the literature that reported the relationship between diet and oral health and oral diseases, in addition to the studies 
assessing the basic nutritional knowledge of an ordinary individual. The researcher with the help of three research assistants and an expert in the nutrition field prepared the first draft of the questionnaire which was composed of 20 items written in the participants' native language (i.e., the Arabic language). Nine experts in assessment, nutrition, and dentistry have verified the content and face validity of the questionnaire. A pilot study including 22 subjects from the private dental clinics in Hebron city was conducted to assess the internal reliability test of the questionnaire using SPSS ${ }^{\mathrm{TM}}$ version 21. Cronbach's alpha coefficient was 0.85 , indicating the items have acceptable internal consistency. The final version of the questionnaire included 17 items. The items were presented as statements; and the subjects have to select if each statement is "correct," "false," or "I do not know." In the analysis phase, the answers were coded as the following: (1 mark for the correct answer and 0 marks for the false or "I do not know" answers). The sum of the answers was calculated to get the total score out of seventeen for each subject. It is important to add that the psychometric properties of the 17-item questionnaire developed to assess the participants' nutritional knowledge were further examined using the Rasch Measurement model. According to Bond and Fox [17], Rasch measurement model is used for research instruments validation because it ensures that the research instruments have met the fundamental measurement requirements of research instrument, for both the whole instrument and the individual item as well as person [17]. The collected data were analyzed using the Winsteps software program, version 4.1.0 [18]. Overall, the Rasch analyses revealed that the questionnaire met the measurement requirements as reported in the results section below.

2.3.2. Nutritional and Oral Health Status Assessment. Nutritional status was evaluated using anthropometric measurements, diet intake, and dietary practices. The anthropometric measurement included body weight and height, which were done following the standard protocol documented in Lee and Nieman [19]. The body mass index was calculated for each participant and the WHO cutoff points were used to categorize the nutritional status (obese, overweight, normal weight, and underweight) [19]. Food frequency questionnaire (FFQ) was used to assess the dietary intake. The questionnaire was validated in the Palestinian context (i.e., current study setting) by Hamdan et al. [20]. The questionnaire also included questions about nutritional practices to get detailed information about the eating patterns and food choices of the participants. The evaluation of overall oral health, oral hygiene, gum health, and presence of calcification was done by the dentists from the selected clinic. The rating score for oral hygiene, gum health, and overall oral health was done following the standard procedures from Carranza's Clinical Periodontology for oral health assessment using Periodontal examination chart which include Plaque index, Gingival index, mobility of the teeth, presence of calcification, and teeth furcation. The end score divided the oral health status into poor, fair, good, and excellent; for calcification, the assessment depends on the presence or absence of calcification [21].

2.4. Statistical Analysis. The Statistical Package for the Social Sciences SPSS ${ }^{\mathrm{TM}}$, version 21 , was used to analyze the collected data [22]. The normality test was done for the nutritional knowledge scores using the Kolmogorov-Smirnov test. Descriptive analysis including the means and the standard deviations was used to analyze the data pertained to continuous dependent and independent variables. The categorical data were described by percentages. The independent samples $t$-test and ANOVA test were conducted to examine the differences in the total score of the nutritional knowledge due to selected independent variables at alpha $<0.05$. The Winsteps software program, version 4.1.0, was used to conduct the Rasch analysis to further examine the psychometric properties of the developed questionnaire on nutritional knowledge [23].

\section{Results}

3.1. Subjects' Characteristics. The total number of the participants invited and agreed to join the study was 169 . Among them, 19 participants were excluded due to missing data. Only 150 participants were included in the final analysis. Table 1 shows the demographic characteristics of the sample presented in frequencies and percentages.

The results revealed that smoking prevalence among males is higher compared to females $(p<0.05)$. Among the total sample, 13 patients reported presence of chronic diseases: 2 asthma, 5 diabetes, 4 hypertension, 1 thyroidism, and 1 heart disease. The cigarettes smokers' percentage is $52.1 \%$ of the total participants.

3.2. Participants' Oral Health Practices. Table 2 presents the oral care practices among the study sample. There was significant relationship between oral health practices and gender for the following items: "cleaning the teeth regularly," "using teeth floss," and "visiting the dentist for checking every 6 months." The female participants recorded higher percentages in the aforementioned practices than the males. Females were found to use complementary or alternative methods such as using of salt, lemon, cloves, and cardamom in cleaning their teeth more as compared to males.

3.3. Dietary Habits. Dietary habits of the participants are presented in Table 3. There was significant relationship between dietary habits and gender only for "daily consumption of milk and its dairy products," $p<0.05$, where females tended to consume more milk daily and dairy products compared to males.

Table 4 presents the results of the participants' oral health status. Oral hygiene was significantly associated with gender, $p<0.05$. The item "good" oral hygiene was higher in females than males. General oral health was also lower in males than females. 
TABle 1: Participants sociodemographic characteristics presented in numbers and percentages.

\begin{tabular}{|c|c|c|c|}
\hline Demographic characteristics & & Number $(N)$ & Percentage $(\%)$ \\
\hline \multirow{2}{*}{ Gender } & Male & 44 & 32.8 \\
\hline & Female & 90 & 67.2 \\
\hline \multirow{4}{*}{ Marital status } & Single & 60 & 44.8 \\
\hline & Married & 70 & 52.2 \\
\hline & Divorced & 3 & 2.2 \\
\hline & Widowed & 1 & 0.7 \\
\hline \multirow{3}{*}{ Area of living } & City & 81 & 60.4 \\
\hline & Village & 49 & 36.6 \\
\hline & Camp & 4 & 3 \\
\hline \multirow{3}{*}{ Educational level } & Secondary & 51 & 38.1 \\
\hline & University & 73 & 54.5 \\
\hline & Postgraduate studies & 4 & 3 \\
\hline \multirow{4}{*}{ Monthly income } & Less than 1500 NIS & 26 & 19.4 \\
\hline & 1500-3000 NIS & 47 & 35.1 \\
\hline & $3000-4500$ NIS & 29 & 21.6 \\
\hline & More than 5000 NIS & 28 & 20.9 \\
\hline
\end{tabular}

NIS: New Israeli Shekel.

3.4. Nutrition Knowledge Score. The Rasch measurement model was used to examine the psychometric properties for the questionnaire developed to measure the participants' nutritional knowledge. Overall, the Rasch analyses showed that the research instrument has met the measurement requirements. The item and person reliability indices and unidimensionality through three indicators (item polarity, item fit, and PCA residuals) were examined as shown in Table 5 . Table 5 shows that the reliability of item difficulty measures was very high (0.98) which indicates that replicability of the item difficulty ordering and the item separation index was 6.66, greater than $>2$ [18]. Table 5 also shows that all the item polarities (i.e., pointmeasure correlation coefficients) are positive and ranged from 0.28 to 0.60 , indicating that all the items are moving in the same direction to measure the intended construct [18]. The infit and outfit mean square statistics are also within the recommended range (0.5-1.5) [17], implying that the items are contributing meaningfully to measure the intended construct as expected by the model. However, the outfit square for item one is 1.52 due to misfitting persons. The Zstd values for both the infit and outfit statistics are within the range -2 to +2 , except for infit statistics for item $1(-3.2)$, which is still closer to the recommended range.

The principal component analysis of residuals is used to ensure if the data fit the model and items are measuring a single unidimensional construct. Table 6 shows that unidimensionality is not violated. The variance explained by the measure is $45.3 \%$, and the largest factor extracted from the residuals is equivalent to 2.0227 units which have the strength of about 2 items [18].

Overall, the participants showed inadequate knowledge about the specific dietary practices and oral health. Table 7 demonstrates that the majority of participates answered the basic nutritional questions correctly; for example, 94.1\% knew the answer for question 1, "food plays an important role in the teeth health," and $93.3 \%$ gave the correct answer for question 10, "brushing or riddling the teeth after every meal reduces the decay." On the other hand, the participants were not able to give the correct answers to other specific questions; for example, $84.4 \%$ wrongly answered question 17 , "eating nuts with cariogenic foods protects the teeth," and $76.3 \%$ wrongly answered question 6; "increasing the number of the meals increases dental caries."

The differences in the level of nutrition awareness and sociodemographic (age, gender, and marital status) were not significant. However, the monthly income shows significant relationship with awareness $(p<0.05)$. Patients with monthly income of more than 5000 have higher awareness scores. Awareness scores of females were also higher than those of males; however, no significance was noticed.

In terms of the relationship between nutrition awareness and oral health, there was no significant relationship between awareness level and oral health or oral hygiene.

Table 8 shows the relationship between the dietary intake with the oral and gum health. Participants with poor gum health have shown significant higher sugar intake while the relationship between oral health and sugar intake was found in patients with poor oral health; however, the relationship did not reach the significant level.

\section{Discussion}

This study aimed at assessing the level of nutritional awareness (related to oral health) and its relationship with oral and dental health among adult patients visiting dental clinics in Palestine. Overall, the results of the study revealed that the study sample lacked the essential nutritional knowledge indicated by their low scores on the given items regardless of their demographic characteristics. However, the level of income showed significant difference in the mean scores of nutritional knowledge, supported by the significant mean differences among the groups. 
TABLE 2: Oral health practices according to gender presented in $n(\%)$.

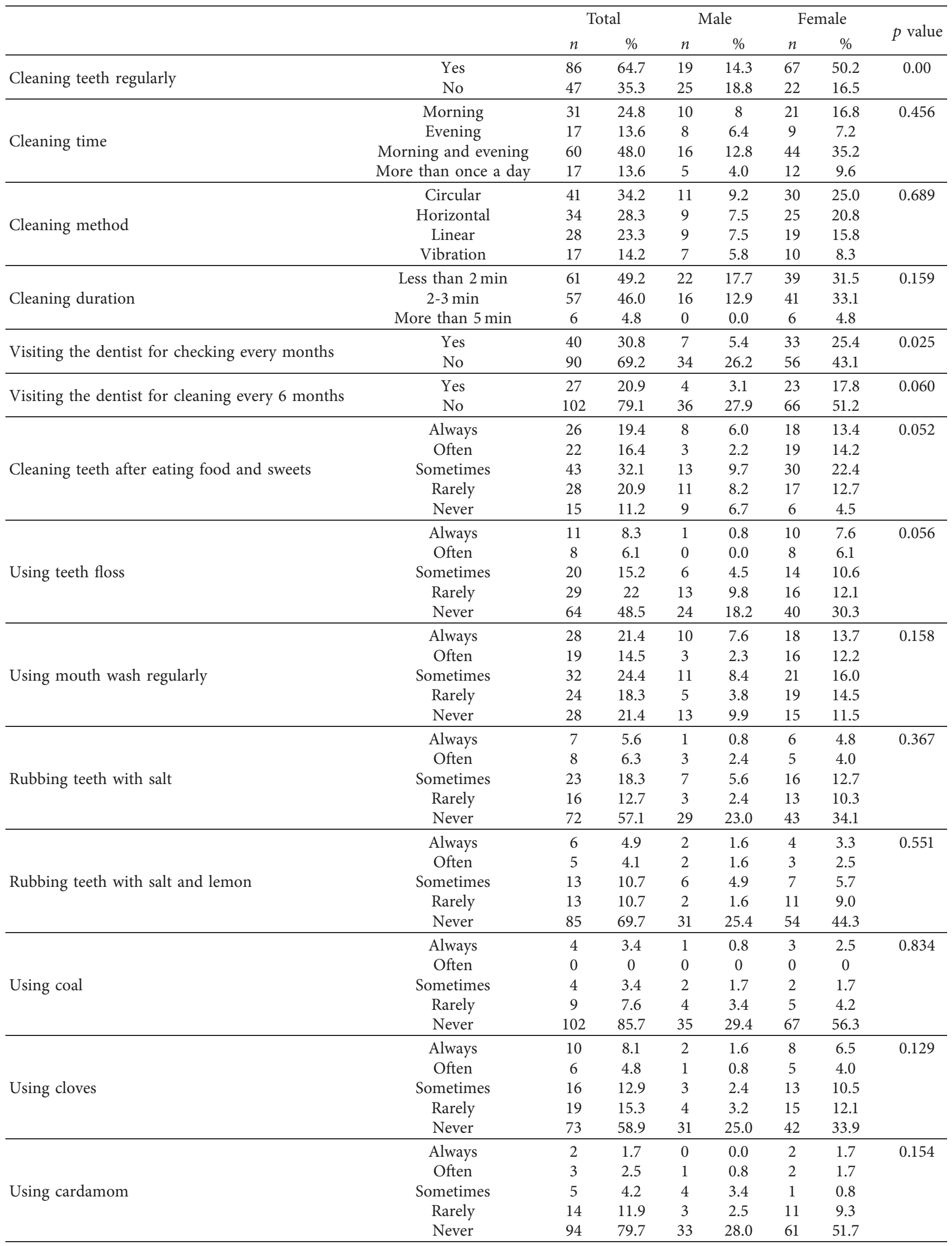


TABLE 3: Dietary habits and practices according to gender presented in $n$ (\%).

\begin{tabular}{|c|c|c|c|c|c|c|c|c|}
\hline & & \multicolumn{2}{|c|}{ Total } & \multicolumn{2}{|c|}{ Male } & \multicolumn{2}{|c|}{ Female } & \multirow{2}{*}{$p$ value } \\
\hline & & $n$ & $\%$ & $n$ & $\%$ & $n$ & $\%$ & \\
\hline \multirow{5}{*}{ Are the meals consistent throughout the days } & Always & 15 & 11.2 & 5 & 3.7 & 10 & 7.5 & 0.727 \\
\hline & Often & 51 & 38.1 & 17 & 12.7 & 34 & 25.4 & \\
\hline & Sometimes & 34 & 25.4 & 10 & 7.5 & 24 & 17.9 & \\
\hline & Rarely & 27 & 20.1 & 11 & 8.2 & 16 & 11.9 & \\
\hline & Never & 7 & 5.2 & 1 & 0.7 & 6 & 4.5 & \\
\hline \multirow{5}{*}{ Do you eat fresh fruits daily (as whole or juiced) } & Always & 40 & 30.1 & 14 & 10.5 & 26 & 19.5 & 0.978 \\
\hline & Often & 37 & 27.8 & 12 & 9.0 & 25 & 18.8 & \\
\hline & Sometimes & 41 & 30.8 & 14 & 10.5 & 27 & 20.3 & \\
\hline & Rarely & 12 & 9.0 & 3 & 2.3 & 9 & 6.8 & \\
\hline & Never & 3 & 2.3 & 1 & 0.8 & 2 & 1.5 & \\
\hline \multirow{5}{*}{ Do you eat vegetables daily (as raw or cooked) } & Always & 47 & 35.6 & 16 & 12.1 & 31 & 23.5 & 0.983 \\
\hline & Often & 32 & 24.2 & 11 & 8.3 & 21 & 15.9 & \\
\hline & Sometimes & 34 & 25.8 & 10 & 7.6 & 24 & 18.2 & \\
\hline & Rarely & 14 & 10.6 & 5 & 3.8 & 9 & 6.8 & \\
\hline & Never & 5 & 3.8 & 2 & 1.5 & 3 & 2.3 & \\
\hline \multirow{5}{*}{ Do you eat brown bread } & Always & 16 & 12.0 & 4 & 3.0 & 12 & 9.0 & 0.258 \\
\hline & Often & 16 & 12.0 & 3 & 2.3 & 13 & 9.8 & \\
\hline & Sometimes & 25 & 18.8 & 12 & 9.0 & 13 & 9.8 & \\
\hline & Rarely & 33 & 24.8 & 9 & 6.8 & 24 & 18.0 & \\
\hline & Never & 43 & 32.3 & 16 & 12.0 & 27 & 20.3 & \\
\hline \multirow{5}{*}{ Do you eat processed meat } & Always & 6 & 4.5 & 4 & 3.0 & 2 & 1.5 & 0.216 \\
\hline & Often & 10 & 7.5 & 2 & 1.5 & 8 & 6.0 & \\
\hline & Sometimes & 34 & 25.4 & 14 & 10.4 & 20 & 14.9 & \\
\hline & Rarely & 38 & 28.4 & 10 & 7.5 & 28 & 20.9 & \\
\hline & Never & 46 & 34.3 & 14 & 10.4 & 32 & 23.9 & \\
\hline \multirow{5}{*}{ Do you eat fast food } & Always & 17 & 12.8 & 6 & 4.5 & 11 & 8.3 & 0.712 \\
\hline & Often & 23 & 17.3 & 8 & 6.0 & 15 & 11.3 & \\
\hline & Sometimes & 42 & 31.6 & 15 & 11.3 & 27 & 20.3 & \\
\hline & Rarely & 32 & 24.1 & 7 & 5.3 & 25 & 18.8 & \\
\hline & Never & 19 & 14.3 & 7 & 5.3 & 12 & 9.0 & \\
\hline \multirow{5}{*}{ Do you drink milk and its constitutes daily } & Always & 33 & 24.6 & 6 & 4.5 & 27 & 20.1 & 0.022 \\
\hline & Often & 32 & 23.9 & 15 & 11.2 & 17 & 12.7 & \\
\hline & Sometimes & 29 & 21.6 & 6 & 4.5 & 23 & 17.2 & \\
\hline & Rarely & 19 & 14.2 & 10 & 7.5 & 9 & 6.7 & \\
\hline & Never & 21 & 15.7 & 7 & 5.2 & 14 & 10.4 & \\
\hline \multirow{5}{*}{ Do you drink enough water (10 cups and more) } & Always & 38 & 28.8 & 12 & 9.1 & 26 & 19.7 & \\
\hline & Often & 35 & 26.5 & 13 & 9.8 & 22 & 16.7 & \\
\hline & Sometimes & 41 & 31.1 & 14 & 10.6 & 27 & 20.5 & 0.776 \\
\hline & Rarely & 12 & 9.1 & 2 & 1.5 & 10 & 7.6 & \\
\hline & Never & 6 & 4.5 & 2 & 1.5 & 4 & 3.0 & \\
\hline \multirow{5}{*}{ Do you watch your calorie intake within a meal } & Always & 9 & 6.8 & 2 & 1.5 & 7 & 5.3 & 0.386 \\
\hline & Often & 14 & 10.6 & 3 & 2.3 & 11 & 8.3 & \\
\hline & Sometimes & 21 & 15.9 & 6 & 4.5 & 15 & 11.4 & \\
\hline & Rarely & 26 & 19.7 & 7 & 5.3 & 19 & 14.4 & \\
\hline & Never & 62 & 47.0 & 26 & 19.7 & 36 & 27.3 & \\
\hline \multirow{5}{*}{ Do you eat nuts at least twice a week } & Always & 30 & 22.4 & 16 & 11.9 & 14 & 10.4 & 0.072 \\
\hline & Often & 29 & 21.6 & 10 & 7.5 & 19 & 14.2 & \\
\hline & Sometimes & 36 & 26.9 & 9 & 6.7 & 27 & 20.1 & \\
\hline & Rarely & 28 & 20.9 & 7 & 5.2 & 21 & 15.7 & \\
\hline & Never & 11 & 8.2 & 2 & 1.5 & 9 & 6.7 & \\
\hline \multirow{5}{*}{ Do you eat fish regularly twice a week } & Always & 15 & 11.2 & 8 & 6.0 & 7 & 5.2 & 0.233 \\
\hline & Often & 15 & 11.2 & 7 & 5.2 & 8 & 6.0 & \\
\hline & Sometimes & 30 & 22.4 & 9 & 6.7 & 12 & 15.7 & \\
\hline & Rarely & 45 & 33.6 & 13 & 9.7 & 32 & 23.9 & \\
\hline & Never & 29 & 21.6 & 7 & 5.2 & 22 & 15.4 & \\
\hline
\end{tabular}


TABLE 4: Characteristics of oral health according to gender presented in $n(\%)$.

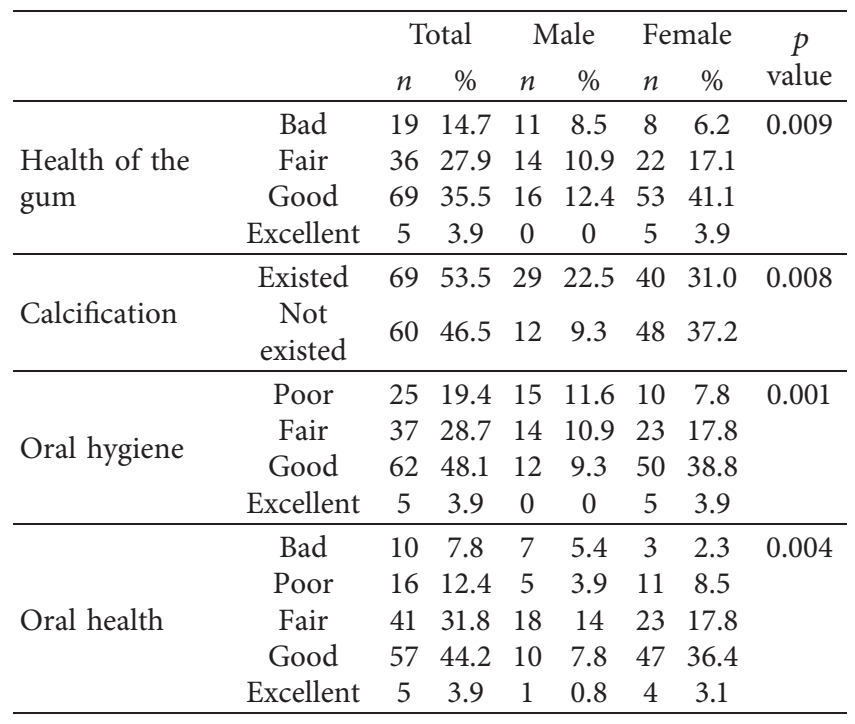

The overall mean score of the nutritional knowledge related to oral health was insufficient. The current study is unique because it has assessed nutritional knowledge in oral health, whereas many other studies have focused on knowledge, attitude, and practices related to oral health in general, mainly hygienic practices. A study conducted among nutrition and dietetic students in India highlighted low dental nutrition knowledge among nutrition/dietetics students [8]. This finding raised the issue that lacking nutrition knowledge related to oral health is a problem even among health professionals. By comparing the findings of this study with other studies focusing on oral health, almost similar trends were reported. For example, Szatco and his colleagues reported that Polish mothers lacked nutrition knowledge which affected adversely their kids' oral health [24]. Another study showed that Jordanian adults' poor level of knowledge related to periodontal diseases and the study recommended more educational programs to improve oral health awareness [25].

The study sample was comparably distributed according to gender: the study found no significant differences between males and females in the level of knowledge and awareness even though females usually recorded higher level of awareness and knowledge. Available literature reported a higher nutritional knowledge among females compared to males [26-29], and females showed more interest in nutrition and health, while no significant differences in nutrition knowledge and awareness levels between males and females were reported in Sarawak, Malaysia [10]. In terms of oral health, similar trend to the current study was reported; men showed less oral health knowledge compared to women [30]. In a study conducted in Palestine, significant gender differences were reported in knowledge attitude and practices of dental and oral health between males and females [31]. In Kuwait, poor oral health knowledge and practices among male students compared to female students were also reported [30].
4.1. Oral Health Status and Nutrition-Related Factors. The current study found that the relationship between nutrition knowledge and oral health was not significant. Participants with higher nutrition knowledge scores did not have better oral or gum health. However, "good oral health status" was significantly higher in females compared to males. In addition, "bad gum health" in males was significantly higher compared to females. Females reported better oral health compared to men, which may be due to the presence of other factors as smoking. Numerous studies have shown that tobacco use would lead to and increase incidences and severity of periodontal diseases and higher rates of tooth loss. The adverse effects of cigarette smoking and other forms of tobacco are numerous, and tobacco use has been associated with gingival, oral mucosa, and dental alterations [32]. Females gained higher scores on nutrition knowledge and got better practices related to oral health compared to males, which illustrate that females may be more interested in nutrition and oral health than men [33].

There were no significant differences between body mass index (BMI) and oral health, gum health, and oral hygiene. However, another study reported the association between body mass index (BMI) and oral health among adults; obesity and abdominal obesity were associated with increased prevalence of periodontal disease, while being underweight was associated with decreased prevalence of periodontal diseases. It concluded that obesity could be a potential risk factor for periodontal disease [34]. Chafee and Weston suggested a bidirectional relationship between obesity and periodontal diseases, as obesity, insulin resistance, and periodontal diseases all are accompanied with hyperinflammatory status, oxidative stress, and increased level of adipocytokines [35].

The frequencies and percentages of correct answers were variable among the items. General questions reported higher percentages of correct answers compared to oral nutrition specific items. Questions 1 and 10 asked about the role of food in oral health and brushing teeth preventing caries, respectively. Both items asked about basic general knowledge, which is well known to most of age groups. Similar findings were reported in different studies targeting different populations. Among school teachers in Saudi Arabia, satisfactory level of knowledge was found in general oral health questions such as oral hygiene practices [36]. Majority of school children was found to be familiar with the effects of oral hygiene on oral health [37].

However, high percentages of participants gave wrong answers to questions $2,3,4,7,12$, and 13 asking about sugar and dental caries. Specifically, they were asked about the effect of sugars on dental caries, effect of other types of sweetener, frequency and the length of exposure between sugar and teeth, eating more frequent meals, and increasing the risk of caries by consuming sticky dessert which stays at the oral cavity for longer time. Such findings were surprisingly reported in Bapat et al., who found lack of knowledge of similar questions among nutritionist and dietetic students. [8].

Questions 11, 16, and 7 focused on protective dietary factors against dental caries (i.e., nutrients that play 
TABLE 5: Items measures, fit statistics, and point-measure correlation coefficient.

\begin{tabular}{|c|c|c|c|c|c|c|c|c|}
\hline No. & Item & Measure & S.E & $\begin{array}{c}\text { Infit } \\
\text { MNSQ }\end{array}$ & ZSTD & $\begin{array}{l}\text { Outfit } \\
\text { MNSQ }\end{array}$ & ZSTD & $\begin{array}{l}\text { PT-measure } \\
\text { CORR }\end{array}$ \\
\hline 1 & Food plays an important role in the oral health & -3.36 & 0.46 & 1.20 & 0.6 & 1.52 & 0.9 & 0.29 \\
\hline 2 & Sugar is one of the food elements that causes dental caries & -2.25 & 0.31 & 1.08 & 0.4 & 0.90 & -0.1 & 0.38 \\
\hline 3 & Chewing free-sugar gum reduces dental caries & 0.88 & 0.20 & 0.99 & -0.1 & 1.03 & 0.2 & 0.44 \\
\hline 4 & $\begin{array}{c}\text { Using artificial sweeteners in candies and juices reduces the } \\
\text { dental caries }\end{array}$ & 1.84 & 0.23 & 1.01 & 0.1 & 0.85 & -0.5 & 0.40 \\
\hline 5 & $\begin{array}{c}\text { Drinking fruit juice cause dental caries more than eating the } \\
\text { whole fruit }\end{array}$ & 1.38 & 0.21 & 1.06 & 0.6 & 1.01 & 0.1 & 0.38 \\
\hline 6 & Increasing the number of the meals increases dental caries & 1.9 & 0.23 & 1.08 & 0.7 & 0.99 & 0.1 & 0.35 \\
\hline 7 & $\begin{array}{c}\text { The frequency of eating sugar is more cariogenic compared } \\
\text { to the amount of the sugar }\end{array}$ & 0.22 & 0.20 & 1.00 & 0.1 & 1 & 0.1 & 0.44 \\
\hline 8 & Food leftovers in the mouth are associated with dental caries & -2.45 & 0.33 & 1.02 & 0.2 & 0.9 & -0.1 & 0.40 \\
\hline 9 & $\begin{array}{l}\text { Eating sweets with meals is better than eating sweets between } \\
\text { meals on dental caries }\end{array}$ & 1.55 & 0.21 & 0.96 & -0.4 & 0.95 & -0.1 & 0.43 \\
\hline 10 & $\begin{array}{c}\text { Brushing or flossing the teeth after every meal reduces the } \\
\text { caries }\end{array}$ & -3.16 & 0.43 & 0.83 & -0.4 & 0.64 & -0.4 & 0.47 \\
\hline 11 & $\begin{array}{c}\text { Drinking milk and dairy products protect the teeth from } \\
\text { caries }\end{array}$ & -1.82 & 0.27 & 1.15 & 0.9 & 1.48 & 1.3 & 0.30 \\
\hline 12 & $\begin{array}{l}\text { Eating sweets that melt in the mouth and swallowed faster } \\
\text { are less harmful than the sweets that stay for a longer time in } \\
\text { the mouth. }\end{array}$ & 0.07 & 0.20 & 0.77 & -3.2 & -0.71 & 2.0 & 0.60 \\
\hline 13 & $\begin{array}{c}\text { Sticky sweets increase the probability of teeth decay } \\
\text { compared to melty sweets }\end{array}$ & -0.08 & 0.20 & 0.92 & -1.1 & -0.81 & 1.2 & 0.51 \\
\hline 14 & $\begin{array}{l}\text { Foods that increase the saliva secretion increase the } \\
\text { possibility for tooth decay }\end{array}$ & 1.79 & 0.22 & 0.90 & $-0.8 \mid$ & 0.79 & -0.8 & 0.46 \\
\hline 15 & $\begin{array}{c}\text { Reduction of food eaten before bed helps protecting from } \\
\text { dental caries }\end{array}$ & -0.45 & 0.20 & 0.91 & -1.0 & 0.84 & -0.9 & 0.50 \\
\hline 16 & $\begin{array}{c}\text { The presence of proteins and fats with sugar-containing } \\
\text { meals decrease the decay }\end{array}$ & 1.38 & 0.21 & 1.18 & 1.8 & 1.23 & 1.0 & 0.30 \\
\hline 17 & $\begin{array}{l}\text { Eating nuts with tooth decay-causing foods protects the teeth } \\
\text { from decay }\end{array}$ & 2.55 & 0.27 & 1.03 & 0.3 & 1.35 & 1.1 & 0.28 \\
\hline Means & & 0.00 & 0.26 & 1.01 & -0.1 & 1.00 & $0 .-1$ & \\
\hline \multicolumn{9}{|c|}{ Reliability and separation } \\
\hline \multicolumn{2}{|c|}{ Item reliability } & 0.98 & & & & & & \\
\hline \multicolumn{2}{|c|}{ Item separation } & 6.66 & & & & & & \\
\hline \multicolumn{2}{|c|}{ Person reliability } & 0.71 & & & & & & \\
\hline \multicolumn{2}{|c|}{ Person separation } & 1.57 & & & & & & \\
\hline
\end{tabular}

TABLE 6: Standardized residual variance in eigenvalue units (= item information units).

\begin{tabular}{lccc}
\hline & Eigenvalue & Observed (\%) & Expected (\%) \\
\hline Total raw variance in observations $=$ & 31.1017 & 100.0 & 100.0 \\
Raw variance explained by measures & 14.1017 & 45.3 & 44.9 \\
Raw variance explained by persons $=$ & 5.3887 & 17.3 & 17.2 \\
Raw variance explained by items $=$ & 8.7129 & 28.0 & 27.7 \\
Raw unexplained variance (total) $=$ & 17.0000 & 54.7 & 55.1 \\
Unexplained variance in 1st contrast $=$ & 2.0227 & 100.0 & 11.9 \\
\hline
\end{tabular}

protective roles against dental caries if consumed with cariogenic food, including dairy products, nuts, and presence of protein or fat with sugars) [3]. The protective effect of dairy products got $84 \%$ of correct answers, while the other items reported much lower percentages of correct answers (31\% and $14.8 \%)$. This variation may be due to the recommendations of drinking milk and dairy products for healthy teeth as a calcium source and not due to their awareness of effect of bioactive compounds and types of polypeptides found on milk and dairy products that have the carioprotective effect [38].

The questions on the role of salivary flow effect and the acidity of food received lower percentage of correct answers $26.7 \%$ and $40.7 \%$ though the questions are dealing with wellknown documented effects. This may be due to lack of nutrition consultation in the dental clinic, or maybe dentists did not focus on dietary behavior that affects oral health and rather they only focused on oral hygienic practices. 
TABLE 7: Frequencies and percentages of correct answers.

\begin{tabular}{|c|c|c|c|c|}
\hline \multirow{2}{*}{ Knowledge items } & \multicolumn{2}{|c|}{$\mathrm{T}$} & \multicolumn{2}{|c|}{$\mathrm{F}$} \\
\hline & $n$ & $(\%)$ & $n$ & $(\%)$ \\
\hline 1-Food plays an important role in the oral health. & 127 & 94.1 & 7 & 5.2 \\
\hline 2-Sugar is one of the most food element that cause dental caries. & 119 & 88.1 & 15 & 11.1 \\
\hline 3-Chewing free-sugar gum reduces dental caries. & 54 & 40 & 80 & 59.3 \\
\hline 4-Using artificial sweeteners in candies and juices reduces the dental caries. & 32 & 23.7 & 102 & 75.6 \\
\hline 5-Drinking fruit juice causes dental caries more than eating the whole fruit. & 55 & 40.7 & 79 & 58.5 \\
\hline 6-Increasing the number of the meals increases dental caries. & 31 & 23 & 103 & 76.3 \\
\hline 7-The frequency of eating sugar is more cariogenic compared to the amount of the sugar. & 71 & 52.6 & 63 & 46.7 \\
\hline 8 -Food leftovers in the mouth are associated with dental caries. & 121 & 89.6 & 13 & 9.6 \\
\hline 9-Eating sweets with meals is better than eating sweets between meals on dental caries. & 38 & 28.1 & 96 & 71.1 \\
\hline 10-Brushing or flossing the teeth after every meal reduces the caries. & 126 & 93.3 & 8 & 5.9 \\
\hline 11-Drinking milk and dairy products protect the teeth from caries. & 114 & 84.4 & 20 & 14.8 \\
\hline $\begin{array}{l}\text { 12-Eating sweets that melt in the mouth and swallowed faster is less harmful than the sweets that stay for a longer } \\
\text { time in the mouth. }\end{array}$ & 75 & 55.6 & 59 & 43.7 \\
\hline 13-Sticky sweets increase the probability of teeth decay comparing to melty sweets. & 79 & 58.5 & 55 & 40.7 \\
\hline 14-Foods that increase the saliva secretion increase the possibility for tooth decay. & 36 & 26.7 & 98 & 72.6 \\
\hline 15-Reduction of food eaten before bed helps protecting from dental caries. & 88 & 65.2 & 46 & 34.1 \\
\hline 16-The presence of proteins and fats with sugar-containing meals decreases the decay. & 42 & 31.1 & 92 & 68.1 \\
\hline 17-Eating nuts with tooth decay-causing foods protects the teeth from decay. & 20 & 14.8 & 114 & 84.4 \\
\hline
\end{tabular}

TABLE 8: The relationship between oral health and oral hygiene and macronutrients, total calories, and sugar intake.

\begin{tabular}{|c|c|c|c|c|c|c|}
\hline & Unit & $\begin{array}{c}\text { Poor } \\
\text { Mean } \pm \text { sd }\end{array}$ & $\begin{array}{c}\text { Fair } \\
\text { Mean } \pm \text { sd }\end{array}$ & $\begin{array}{c}\text { Good } \\
\text { Mean } \pm \text { sd }\end{array}$ & $\begin{array}{c}\text { Excellent } \\
\text { Mean } \pm \mathrm{sd}\end{array}$ & $p$ value \\
\hline \multicolumn{7}{|l|}{ Oral health } \\
\hline Total calories & Kcal/day & $2750 \pm 1722$ & $1738 \pm 1950$ & $2650 \pm 2149$ & $1732 \pm 1091$ & 0.120 \\
\hline Fat & Gram/day & $118 \pm 75$ & $80 \pm 46$ & $115 \pm 97$ & $106 \pm 20$ & 0.252 \\
\hline Carbohydrates & Gram/day & $297 \pm 204$ & $167 \pm 130$ & $830 \pm 3848$ & $181 \pm 98$ & 0.742 \\
\hline Protein & Gram/day & $37 \pm 46$ & $63 \pm 55$ & $132 \pm 236$ & $86 \pm 83$ & 0.189 \\
\hline Sugar intake & Gram/day & $120 \pm 87$ & $58 \pm 61$ & $80 \pm 76$ & $87 \pm 74$ & 0.079 \\
\hline \multicolumn{7}{|l|}{ Oral hygiene } \\
\hline Total calories & Kcal/day & $2872 \pm 1664$ & $1576 \pm 1004$ & $2555 \pm 2087$ & $2253 \pm 278$ & 0.109 \\
\hline Fat & Gram/day & $127 \pm 70$ & $71 \pm 45$ & $113 \pm 92$ & $103 \pm 13$ & 0.115 \\
\hline Carbohydrates & Gram/day & $306 \pm 202$ & $156 \pm 117$ & $751 \pm 3607$ & $210 \pm 61$ & 0.821 \\
\hline Protein & Gram/day & $37 \pm 44$ & $62 \pm 51$ & $122 \pm 224$ & $105 \pm 55$ & 0.295 \\
\hline Sugar intake & Gram/day & $129 \pm 84$ & $83 \pm 57$ & $65 \pm 76$ & $60 \pm 47$ & 0.011 \\
\hline
\end{tabular}

The rest of questions $6,8,9$, and 15 have asked about the relationship between food presence in oral cavity and tooth decay, including number of meals, food leftover inside the oral cavity, and dessert consumption immediately after meals [3]. The main concept for these 3 items was that the exposure between meals, mainly carbohydrate and sugars in the oral cavity, will increase the risk of decay. These results supported the main finding which was the lack in the specific oral health nutrition information among the study participants.

\section{Conclusion}

Overall, dental patients at dental clinics revealed insufficient nutrition knowledge related to oral health. The participants were unaware of the various aspects of oral nutrition, with the absence of the statistically significant differences between male and female patients. The results of the study recommend educational programs targeting the individuals visiting the dental clinics including all age groups to enhance their nutrition-related knowledge and nutrition practices, which may improve their oral health. The study suggests including oral health nutrition consultation regularly and continuously at dental clinics, schools, and any other possible places. Further research is needed utilizing different study designs (follow-up and longitudinal and intervention designs) to determine the effect of poor and good nutrition practices on oral health in short- and long-term practices. Further research is needed to determine effective intervention programs that can be implemented in the Palestinian dental clinics.

\section{Data Availability}

The data are available upon request from the corresponding author.

\section{Conflicts of Interest}

The authors declare that there are no conflicts of interest regarding the publication of this paper. 


\section{Acknowledgments}

The authors would like to acknowledge the dental clinics staff and the dentists who helped us in the oral assessment and facilitated the data collection. The authors would like to express their gratitude to the patients who agreed to participate in this study. The authors also thank all coresearchers and fieldworkers involved in this study.

\section{References}

[1] P. E. Petersen, D. Bourgeois, H. Ogawa, S. Estupinan-Day, and C. Ndiaye, "The global burden of oral diseases and risks to oral health," Bulletin of the World Health Organization, vol. 83, no. 9, pp. 661-669, 2005.

[2] M. Nawaz and M. Jabar, "Association of systemic diseases on tooth loss and oral health," Journal of Biomedical Sciences, vol. 4, no. 1, 2015.

[3] L. K. Mahan and J. L. Raymond, Krause's Food \& the Nutrition Care Process-E-Book, Elsevier Health Sciences, Philadelphia, PA, USA, 2016.

[4] L. Zhan, "Rebalancing the caries microbiome dysbiosis: targeted treatment and sugar alcohols," Advances in Dental Research, vol. 29, no. 1, pp. 110-116, 2018.

[5] G. Scardina and P. Messina, "Good oral health and diet," BioMed Research International, vol. 2012, Article ID 720692, 8 pages, 2012.

[6] P. Lingstrom, J. Van Houte, and y.S. Kashket, "Food starches and dental caries," Critical Reviews in Oral Biology \& Medicine, vol. 11, p. 366380, 2000.

[7] P. P. Hujoel and P. Lingström, "Nutrition, dental caries and periodontal disease: a narrative review," Journal of Clinical Periodontology, vol. 44, pp. 79-84, 2017.

[8] S. Bapat, K. Asawa, N. Bhat et al., "Assessment of dental nutrition knowledge among nutrition/dietetics students," Journal of Clinical and Diagnostic Research, vol. 10, p. 37, 2016.

[9] I. Spronk, C. Kullen, C. Burdon, and H. O'Connor, "Relationship between nutrition knowledge and dietary intake," British Journal of Nutrition, vol. 111, no. 10, pp. 1713-1726, 2014.

[10] C. W. Lian, T. S. Phing, C. S. Chat, B. C. Shin, L. H. Baharuddin, and Z. Jalil, "Oral health knowledge, attitude and practice among secondary school students in Kuching, Sarawak," Archives of Orofacial Sciences, vol. 5, pp. 9-16, 2010.

[11] M. Humagain, "Evaluation of knowledge, attitude and practice (KAP) about oral health among secondary level students of rural Nepal-a questionnaire study," Webmed Centeral, vol. 2, no. 3, Article ID WMC001805, 2011.

[12] E. Smyth, F. Caamaño, and P. Fernández-Riveiro, "Oral health knowledge, attitudes and practice in 12-year-old schoolchildren," Medicina Oral, Patología Oral Y Cirugía Bucal, vol. 12, pp. 614-620, 2007.

[13] B. Suresh, T. Ravishankar, T. Chaitra, A. Mohapatra, and V. Gupta, "Mother's knowledge about pre-school child's oral health," Journal of Indian Society of Pedodontics and Preventive Dentistry, vol. 28, pp. 282-291, 2010.

[14] L. Zhu, P. E. Petersen, H.-Y. Wang, J.-Y. Bian, and B.-X. Zhang, "Oral health knowledge, attitudes and behaviour of adults in China," International Dental Journal, vol. 55, no. 4, pp. 231-241, 2005.

[15] G. Murthy and U. Mohandas, "The knowledge, attitude and practice in prevention of dental caries amongst pediatricians in Bangalore: a cross-sectional study," Journal of Indian Society of Pedodontics and Preventive Dentistry, vol. 28, no. 2, pp. 100-110, 2010.

[16] A. A. Al Subait, M. Alousaimi, A. Geeverghese, A. Ali, and A. El Metwally, "Oral health knowledge, attitude and behavior among students of age 10-18 years old attending Jenadriyah festival Riyadh; a cross-sectional study," The Saudi Journal for Dental Research, vol. 7, no. 1, pp. 45-50, 2016.

[17] T. G. Bond and C. M. Fox, Applying the Rasch Model: Fundamental Measurement in the Human Sciences, Routledge, Abingdon, UK, 3rd edition, 2015.

[18] J. M. Linacre, "Detecting multidimensionality in Rasch data using winsteps table 23," 2018, http://tinyurl.com/yxzomgwy.

[19] R. Lee and D. Nieman, Anthropometry, Nutritional Assessment, vol. 3, pp. 164-169, McGraw-Hill, New York, NY, USA, 1996.

[20] M. Hamdan, C. Monteagudo, M.-L. Lorenzo-Tovar, J.-A. Tur, F. Olea-Serrano, and M. Mariscal-Arcas, "Development and validation of a nutritional questionnaire for the Palestine population," Public Health Nutrition, vol. 17, no. 11, pp. 2512-2518, 2013.

[21] M. G. Newman, H. Takei, P. R. Klokkevold, and F. A. Carranza, Carranza's Clinical Periodontology, Elsevier health sciences, Philadelphia, PA, USA, 2011.

[22] A. Field, Discovering Statistics Using IBM SPSS Statistics, SAGE, Thousand Oaks, CA, USA, 2013.

[23] J. M. Linacre and B. D. Wright, "Winsteps \& facets rasch software," 2000, http://www.winsteps.com/index.htm.

[24] F. Szatko, M. Wierzbicka, E. Dybizbanska, I. Struzycka, and E. Iwanicka-Frankowska, "Oral health of polish three-yearolds and mothers' oral health-related knowledge," Community dental health, vol. 21, no. 2, pp. 175-180, 2004.

[25] D. Q. Taani, "Periodontal awareness and knowledge, and pattern of dental attendance among adults in Jordan," International Dental Journal, vol. 52, no. 2, pp. 94-98, 2002.

[26] P. Mirmiran, F. Mohammadi-Nasrabadi, N. Omidvar et al., "Nutritional knowledge, attitude and practice of Tehranian adults and their relation to serum lipid and lipoproteins: tehran lipid and glucose study," Annals of Nutrition and Metabolism, vol. 56, no. 3, pp. 233-240, 2010.

[27] W. Lin, C.-M. Hang, H.-C. Yang, and M.-H. Hung, "2005-2008 Nutrition and Health Survey in Taiwan: the nutrition knowledge, attitude and behavior of 19-64 years old adults," Asia Pacific Journal of Clinical Nutrition, vol. 20, pp. 309-318, 2011.

[28] J. Zhang, A.-q. Xu, J.-x. Ma et al., "Dietary sodium intake: knowledge, attitudes and practices in Shandong Province, China," PLoS One, vol. 8, Article ID e58973, 2013.

[29] M. Naeeni, S. Jafari, M. Fouladgar et al., "Nutritional knowledge, practice, and dietary habits among school children and adolescents," International Journal of Preventive Medicine, vol. 5, no. 14, pp. 171-179, 2014.

[30] J. M. Al-Ansari and S. Honkala, "Gender differences in oral health knowledge and behavior of the health science college students in Kuwait," Journal of Allied Health, vol. 36, pp. 41-46, 2007.

[31] E. Kateeb, "Gender-specific oral health attitudes and behaviour among dental students in Palestine," EMHJ-Eastern Mediterranean Health Journal, vol. 16, no. 3, pp. 329-333, 2010.

[32] M. Rad, S. Kakoie, F. N. Brojeni, and N. Pourdamghan, "Effect of long-term smoking on whole-mouth salivary flow rate and oral health," Journal of Dental Research, Dental Clinics, Dental Prospects, vol. 4, pp. 110-119, 2010. 
[33] A.-L. Östberg, A. Halling, and U. Lindblad, "Gender differences in knowledge, attitude, behavior and perceived oral health among adolescents," Acta Odontologica Scandinavica, vol. 57, no. 4, pp. 231-236, 1999.

[34] M. S. Al-Zahrani, N. F. Bissada, and E. A. Borawski, "Obesity and periodontal disease in young, middle-aged, and older adults," Journal of Periodontology, vol. 74, no. 5, pp. 610-615, 2003.

[35] B. W. Chaffee and S. J. Weston, "Association between chronic periodontal disease and obesity: a systematic review and metaanalysis," Journal of Periodontology, vol. 81, no. 12, pp. 1708-1724, 2010.

[36] M. A. Baseer, M. S. Alenazy, M. AlAsqah, M. AlGabbani, and A. Mehkari, "Oral health knowledge, attitude and practices among health professionals in King Fahad Medical city, Riyadh," Dental Research Journal, vol. 9, no. 4, pp. 386-392, 2012.

[37] L. P. Dixit, A. Shakya, M. Shrestha, and A. Shrestha, "Dental caries prevalence, oral health knowledge and practice among indigenous Chepang school children of Nepal," BMC Oral Health, vol. 13, no. 1, pp. 20-29, 2013.

[38] W. R. Aimutis, "Bioactive properties of milk proteins with particular focus on anticariogenesis," The Journal of Nutrition, vol. 134, no. 4, pp. 989S-995S, 2004. 